\title{
HUBUNGAN STATUS GIZI DAN AKTIVITAS FISIK TERHADAP USIA MENARCHE PADA SISWI DI SDN 47/IV KOTA JAMBI TAHUN 2018
}

\author{
The Relationship Between Nutritional Status And Physical Activity To The Age Of \\ Menarche Students In Public Elementary School 47/IV Jambi City In 2018
}

\author{
Valensia Br Napitupulu ${ }^{1}$, Hubaybah² dan Rd. Halim² \\ ${ }^{1}$ Program Sarjana Studi Ilmu Kesehatan Masyarakat Universitas Jambi \\ ${ }^{2}$ Ilmu Kesehatan Masyarakat, Fakultas Kesehatan Masyarakat, Universitas Jambi
}

\begin{abstract}
Abstrak
Menarche merupakan menstruasi yang pertama kali dialami remaja putri, dimana secara fisik ditandai dengan keluarnya darah dari vagina akibat peluruhan lapisan endometrium. Tujuan penelitian ini untuk mengetahui hubungan antara status gizi dan aktivitas fisik terhadap usia menarche pada siswi di Sekolah Dasar Negeri 47/IV Kota Jambi Tahun 2018. Jenis penelitian analitik observasional dengan rancangan cross-sectional. Teknik pengambilan sampel yang digunakan adalah stratified random sampling. Besar sampel sebanyak 65 siswi. Penelitian ini dilaksanakan pada di Sekolah Dasar Negeri 47/IV Kota Jambi pada bulan Maret 2018. Data penelitian aktivitas fisik diperoleh dengan modifikasi kuesioner Physical Activity Questionnaire for Older Children (PAQ-C) dan pengukuran langsung terhadap berat badan dan tinggi badan untuk status gizi. Data dianalisis menggunakan uji Chi-Square. Hasil penelitian menunjukkan sebanyak 55,4\% siswi sudah mengalami menarche normal, 50,8\% siswi dengan status gizi gemuk dan $58,5 \%$ siswi kurang aktif dalam melakukan aktivitas fisik. terdapat hubungan yang bermakna antara status gizi terhadap usia menarche ( $\mathrm{p}$ value $=0,080, \alpha=0,05$ ) dan tidak ada hubungan yang bermakna antara aktivitas fisik terhadap usia menarche ( $\mathrm{p}$ value $=0,026, \alpha=0,05$ ).
\end{abstract}

Kata Kunci : status gizi, aktivitas fisik, usia menarche

\begin{abstract}
Menarche is the first menstruation of a girl, which is marked by vaginal bleeding physically due to the sloughing of endometrial wall. Menarche occurs at 10-16 years old. Menarche in adolescent girls is influenced by endogenous and exogenous factors. The purpose of this study is to explore the correlation between nutritional status and physical activity and the age of menarche of the female students of elementary school number 47/IV at Jambi City in 2018. This is an observational analytic study with crosssectional design. The sampling technique is stratified random sampling. The numbers of samples were 65 female students. The study was conducted at elementary school number 47/IV at Jambi City in March 2018. Physical activity data obtained using the Physical Activity for Older Children (PAQ-C) Questionnaire and by directly measure the body weight and height for nutritional status. Data were analyzed using Chi-Square test. The results of this study showed that $55.4 \%$ of female students had a normal menarche with an average age of menarche of $9.8 \pm 0.81$ years. $50.8 \%$ of female students were fat in nutritional status and $58.5 \%$ were less active in physical activity. There is a significant relationship between nutritional status and the age of menarche ( $\mathrm{p}$ value $=0.080, \alpha=0.05)$ and there is no significant relationship between physical activity and menarche ( $\mathrm{p}$ value $=0.026, \alpha=0.05)$.
\end{abstract}

Keywords: nutritional status, physical activity, menarche age.

Korespondensi : Valensia Br Napitupulu

Email:napitupuluvalensia@yahoo.co.id 


\section{PENDAHULUAN}

Menarche adalah menstruasi pertama yang biasa terjadi dalam rentang usia 10 - 16 tahun atau pada masa awal remaja di tengah masa pubertas sebelum memasuki masa reproduksi ${ }^{1}$. Menarche merupakan perubahan yang menandakan bahwa remaja putri sudah memasuki tahap kematangan organ seksual. Menarche dimulai dari pertumbuhan organ seks sekunder tumbuh berkembang, seperti pembesaran payudara, tumbuh rambut ketiak, panggul membesar serta mulai berkembangnya beberapa organ vital yang siap untuk dibuahi ${ }^{2}$.

Menarche yang terlalu cepat merupakan faktor risiko terjadinya kanker payudara, kanker ovarium, risiko penyakit kardiovaskuler, dan juga menopause yang lebih cepat. Menarche lambat berhubungan dengan osteoporosis. Penelitian kohort yang dilakukan di jepang menunjukkan hasil perempuan yang mengalami menarche lambat (>14 tahun) berhubungan dengan peningkatan risiko kepadatan mineral tulang yang rendah di area pinggul pada wanita yang berusia 40 tahun ke bawah ${ }^{3}$.

Menarche pada remaja putri dipengaruhi oleh beberapa faktor. Beberapa faktor yang mempengaruhi menarche adalah genetik, status gizi, lemak tubuh,aktivitas fisik dan sosial ekonomi ${ }^{3}$. Faktor lain yang mempengaruhi adalah rangsangan psikis. Rangsangan psikis yang dimaksud adalah pengaruh lingkungan, misalnya informasi terkait hal-hal pornografi dan pornoaksi dari berbagai media,perilaku keluarga dan masyarakat serta adat kebiasaan setempat yang menstimulasi kedewasaan ${ }^{4}$.

Asupan zat gizi juga mempengaruhi kematangan seksual pada remaja putri. Remaja putri yang mendapat menarche dini cenderung memiliki berat badan dan tinggi badan yang lebih dibandingkan dengan yang belum menarche pada usia yang sama. Pada umumnya, mereka yang menjadi matang lebih dini akan memiliki Indeks Massa Tubuh (IMT) yang lebih tinggi dan mereka yang yang matang terlambat memiliki IMT lebih kecil pada usia yang sama ${ }^{5}$.

Aktivitas fisik merupakan pergerakan anggota tubuh yang menyebabkan pengeluaran tenaga secara sederhana dan penting bagi pemeliharan fisik, mental, dan kualitas hidup sehat. Aktivitas fisik pada anak usia sekolah dapat berupa aktivitas sehari-hari baik di rumah maupun di sekolah, kebiasaan, hobi maupun latihan fisik dan olahraga. Aktivitas fisik seperti olahraga juga dapat mempengaruhi usia menarche. Hasil penelitian yang dilakukan oleh Rosanti ada hubungan antara aktivitas fisik dengan status menarche memiliki nilai OR 4 yang artinya remaja putri yang tidak pernah atau jarang melakukan aktivitas fisik lebih beresiko 4 kali untuk mengalami menarche lebih cepat dibandingkan remaja putri yang melakukan aktivitas fisik ${ }^{6}$.

usia menarche mengalami pergeseran, perubahan dan mengarah pada usia menarche yang lebih cepat. Penurunan rata-rata usia menarche mulai diketahui pada awal abad ke20. Terlihat pada beberapa penelitian di negara-negara industri benua Amerika dan Eropa dengan ditemukannya penurunan usia menarche sebesar 2-3 bulan tiap dekade dalam kurun waktu 100 sampai 500 tahun terakhir. Di Amerika Serikat, rata-rata usia menarche adalah lebih dari 14 tahun sebelum tahun 1900 dan antara tahun 1988 dan 1994 menurun menjadi 12,43 tahun. Di Benua Eropa, seperti di Portugis, Italia, Spanyol, Venezuela dan Inggris, umur rata-rata menarche untuk remaja putri yang lahir di tahun 1880-1890 adalah 15,0 tahun dan menjadi 12,03 tahun untuk remaja putri yang lahir di tahun 1970-1980³. 
Hasil Riskesdas (2010) berdasarkan laporan responden yang sudah mengalami haid, rata-rata usia menarche di Indonesia 13 tahun (20,0\%) dengan kejadian lebih awal pada usia kurang dari 9 tahun dan yang lebih lambat 20 tahun. Secara nasional rata-rata usia menarche 13-14 tahun terjadi pada 37,5\% anak Indonesia. Menurut hasil SDKI remaja tahun 2012 89\% responden remaja putri mengalami haid pertama pada umur 12-15 tahun dan $7 \%$ responden mengalami menarche pada umur 10-11 tahun. Di provinsi Jambi menarche terjadi rata-rata usia 13-14 tahun $(39,7 \%)^{7}$. Berdasarkan survey awal yang dilakukan oleh peneliti di SDN 47/IV kota Jambi tahun 2017, didapatkan 5 (13,89\%) remaja putri sudah mengalami menarche dengan rata-rata usia menarche 10,2 tahun dari jumlah total 36 orang remaja putri dan didapatkan 1 remaja putri yang menarche pada usia 9 tahun.

Berdasarkan survey awal dan ditunjang oleh berbagai penelitian yang menyatakan faktor-faktor yang mempengaruhi menarche adalah status gizi dan aktivitas fisik, maka penulis memilih Sekolah Dasar untuk melihat penurunan usia menarche. Penulis memilih SDN 47/IV Kota Jambi kelas V dan VI sebagai lokasi penelitian karena merupakan sekolah dengan jumlah murid terbanyak di Kota Jambi tahun ajaran 2017/2018. Berdasarkan data dari Dinas Pendidikan Kota Jambi tahun ajaran 2017/2018, jumlah total peserta didik sampai bulan November 2017 sebanyak 1132 siswa/siswi. SDN 47/IV Kota Jambi juga termasuk ke dalam sosial-ekonomi tinggi, kategori ini diketahui berdasarkan survey awal pada tanggal 16 Agustus 2017 bahwa terlihat banyak remaja putri yang berbadan gemuk,fasilitas sekolah yang mewah seperti fasilitas gedung 3 tingkat dilengkapi AC di setiap kelas,dan saat para remaja putri pulang sekolah hampir rata-rata dijemput menggunakan mobil pribadi.

\section{METODE}

Penelitian ini termasuk jenis penelitian analitik observasional dengan menggunakan rancangan penelitian cross sectional, semua variabel independent dan variabel dependent diamati dan diukur dalam waktu yang bersamaan ${ }^{8}$. Sampel pada penelitian adalah siswi yang sudah mengalami menarche, yakni sebanyak 65 siswi dipilih melalui teknik stratified random sampling pada siswi kelas V dan VI di SDN 47/IV Kota Jambi Tahun 2018.

Instrumen yang digunakan dalam penelitian ini adalah kuesioner, timbangan injak, dan mikrotoise. Kuesioner penelitian berisi data diri responden, berat badan, tinggi badan, serta pertanyaan terkait aktivitas fisik yang menggunakan kuesioner Physical Activity Questionnaire for Older Children (PAQ-C) yang terdiri dari sepuluh pertanyaan untuk mengidentifikasi aktivitas fisik responden.

Pengambilan data penelitian ini dilakukan setelah mendapatkan izin dari sekolah, lalu memberikan penjelasan tentang penelitian yang dilakukan kepada calon responden, meminta kesediaan untuk menjadi responden dan mengisi informed consent, memberikan wawancara terhadap kuesioner dan melakukan pengukuran tinggi dan berat badan, serta memeriksa kembali kelengkapan jawaban kuesioner yang dijawab oleh responden. Data yang diperoleh selanjutnya diolah menggunakan analisis data software SPSS (Statistical Program for School Sciences), analisis univariat dan uji chi square.

\section{HASIL}

Rata-rata usia menarche siswi adalah 9,8 tahun. Usia menarche tercepat adalah 115 
bulan/9,7 tahun dan usia menarche terlambat adalah 141 bulan/11,9 tahun. Siswi yang mengalami menarche normal sebesar 55,4\% (36 orang siswi).

Pengukuran status gizi responden menggunakan pengukuran antropometri Indeks Massa Tubuh (IMT) menurut Umur (IMT/U) dengan standar baku dari WHO tahun 2007. Status gizi IMT/U dibagi menjadi tiga kategori yaitu gemuk (overweight), normal, dan kurus (underweight). Berdasarkan tabel 1 diperoleh hasil bahwa pengukuran status gizi siswi, 50,8 \% (33 orang siswi) adalah satus gizi gemuk (overweight) dan siswi yang status gizi kurus sebesar 7,7 \% (5 orang siswi).

Aktivitas fisik responden didapat dari penjumlahan skor dari kuesioner aktivitas fisik yang kemudian dibagi menjadi dua kategori, yaitu siswi aktif dan siswi kurang aktif. Siswi yang tergolong dalam kategori kurang aktif didapat dari hasil skor aktivitas fisik kurang dari mean dan siswi yang tergolong aktif didapat dari skor aktivitas fisik lebih besar sama dengan mean. siswi kurang aktif melakukan aktivitas fisik sebesar 58,5 \% (38 orang siswi).

Hubungan status gizi terhadap usia menarche siswi dapat dilihat pada Tabel 2. data menunjukkan ada hubungan bermakna antara status gizi terhadap usia menarche siswi (pvalue $=0,026)$. Aktivitas fisik terhadap usia menarche siswi tidak ada hubungan yang bermakna $(p=0,080)$. 
Tabel 1. Karakteristik Responden Berdasarkan Usia Menarche, Status Gizi, dan Aktivitas Fisik pada Siswi di SDN 47/IV Kota Jambi Tahun 2018

\begin{tabular}{ccc}
\hline Karakteristik & $\begin{array}{c}\text { Jumlah } \\
\text { (n) }\end{array}$ & Presentase \\
\hline $\begin{array}{c}\text { Usia Menarche } \\
\text { Prekoks }\end{array}$ & 29 & 44,6 \\
$\begin{array}{c}\text { Normal } \\
\text { Status Gizi }\end{array}$ & 36 & 55,4 \\
$\quad$ Gemuk & 33 & 50,8 \\
(overwight) & & \\
Normal & 27 & 41,5 \\
$\quad$ Kurus & 5 & 7,7 \\
(underweight) & & \\
Aktivitas Fisik & & \\
Kurang Aktif & 38 & 58,5 \\
Aktif & 27 & 41,5 \\
\hline
\end{tabular}

Tabel 2. Hubungan Status Gizi dan Aktivitas Fisik Terhadap Usia Menarche Responden pada Siswi di SDN 47/IV Kota Jambi Tahun 2018

\begin{tabular}{|c|c|c|c|c|c|c|c|}
\hline \multirow[t]{3}{*}{ Variabel } & \multicolumn{4}{|c|}{ Usia Menarche } & \multirow{2}{*}{\multicolumn{2}{|c|}{ Total }} & \\
\hline & \multicolumn{2}{|c|}{$\begin{array}{l}\text { Usia } \\
\text { Prekoks }\end{array}$} & \multicolumn{2}{|c|}{$\begin{array}{l}\text { Usia } \\
\text { Normal }\end{array}$} & & & \\
\hline & $\mathbf{n}$ & $\%$ & $\mathbf{n}$ & $\%$ & $\mathbf{n}$ & $\%$ & \\
\hline \multicolumn{8}{|l|}{ Status Gizi } \\
\hline Gemuk & 20 & 60,6 & 13 & 39,4 & 33 & 100 & \multirow{3}{*}{0,026} \\
\hline Normal & 7 & 25,9 & 20 & 74,1 & 27 & 100 & \\
\hline Kurus & 2 & 40,0 & 3 & 60,0 & 5 & 100 & \\
\hline \multicolumn{8}{|l|}{$\begin{array}{l}\text { Aktivitas } \\
\text { Fisik }\end{array}$} \\
\hline Kurang Aktif & 13 & 34,2 & 25 & 68,8 & 38 & 100 & \multirow[t]{2}{*}{0,080} \\
\hline Aktif & 16 & 59,3 & 11 & 40,7 & 27 & 100 & \\
\hline
\end{tabular}




\section{PEMBAHASAN}

Usia menarche sebagian besar responden dalam penelitian ini tidak jauh berbeda dengan hasil penelitian yang dilakukan oleh Munda (2012), di Sekolah Dasar (SD) dan Sekolah Menengah Pertama (SMP) Kota Manado, menunjukkan bahwa $8,4 \%$ siswi sudah mengalami menarche pada usia 9 tahun dengan rata-rata usia menarche $10.63 \pm$ $0.72^{9}$.

Penelitian yang dilakukan di Sekolah Dasar (SD) dan Sekolah Menengah Pertama (SMP) Islam AS-Syafi'iyah Bekasi Tahun 2013 oleh Kusharisupeni, menunjukkan bahwa 5,3\% siswi sudah mengalami menarche pada usia 9 tahun dengan usia termuda 9,6 tahun serta usia rata-rata $11,24 \pm 0,85$ tahun $^{10}$.

Penelitian terdahulu yang dilakukan di SDN 47/IV Kota Jambi oleh Haryani (2016) menunjukkan bahwa 62,7\% siswi menarche pada usia $<11$ tahun dengan usia rata-rata 10,67 tahun ${ }^{11}$.

Menurut Karapanou ${ }^{3}$ faktor - faktor yang mempengaruhi menarche adalah genetik, status gizi, lemak tubuh, aktivitas fisik dan sosial ekonomi. Faktor lain yang mempengaruhi adalah rangsangan psikis. Rangsangan psikis yang dimaksud adalah pengaruh lingkungan, misalnya informasi terkait hal-hal pornografi dan pornoaksi dari berbagai media, perilaku keluarga dan masyarakat serta adat kebiasaan setempat yang menstimulasi kedewasaan ${ }^{4}$.

Berdasarkan hasil penelitian menunjukkan bahwa proporsi usia menarche siswi menurut status gizi menunjukkan adanya perbedaan. Dari 33 orang siswi yang status gizi gemuk (overweight), 60,6\% mengalami menarche dengan usia prekoks sedangkan, dari 27 siswi yang status gizi normal, 74,1\% mengalami menarche dengan usia normal. Hasil analisis bivariat menunjukkan bahwa terdapat hubungan bermakna antara status gizi dengan usia menarche dengan nilai $\mathrm{p}$ $=0,026$.

Penelitian ini sejalan dengan penelitian Ginarhayu (2002) yang dilakukan pada anak usia 9-15 tahun di Jakarta yang menyatakan ada hubungan antara status gizi dengan menarche. Ginarhayu (2002) menyimpulkan bahwa semakin rendah Indeks Massa Tubuh (IMT) pada remaja putri, maka usia menarche akan semakin lambat. Status gizi yang baik akan meningkatkan IMT pada remaja putri yang berdampak pada menurunnya usia menarche ${ }^{12}$. Penelitian tersebut juga sejalan dengan penelitian Kusharisupeni (2013) yang dilakukan di Bekasi menyatakan ada hubungan antara status gizi dengan usia menarche ${ }^{10}$.

Penelitian tersebut bertentangan dengan penelitian Wulandari (2013) yang dilakukan pada siswi SD dan SMP di Jakarta, Wulandari (2013) menyatakan tidak ada hubungan bermakna antara status gizi dengan usia menarche pada remaja putri. Perbedaan hasil ini dapat terjadi karena adanya faktor lain yang mempengaruhi menarche ${ }^{13}$. Penelitian tersebut sejalan dengan penelitian Putri (2009) yang menyatakan tidak ada hubungan antara usia menarche dengan status gizi dengan $\mathrm{p}$-value $=0,158(>0,05)$, hal ini disebabkan karena banyaknya responden yang diteliti memiliki status gizi kurang. Status gizi kurang disebabkan responden melakukan diet ${ }^{14}$.

Salah satu faktor yang berkaitan erat dengan status gizi yang dapat menyebabkan siswi menarche di SDN 47/IV Kota Jambi Tahun 2018 yaitu status sosial-ekonomi. Faktor sosial ekonomi 
yang berhubungan dengan status menarche terdiri dari faktor pendidikan,pekerjaan, dan pendapatan orangtua yang sejalan dengan pengeluaran kebutuhan konsumsi makanan setiap hari, kemampuan mencukupi gizi keluarga dan uang jajan siswi. Pendidikan terakhir orangtua siswi di SDN 47/IV Kota Jambi Tahun 2018 adalah perguruan tinggi sebesar $63,07 \%$ dan 43,07\% bekerja sebagai PNS/TNI/Polri serta berpenghasilan diatas Rp 1.000.000.

Ras dan suku bangsa berhubungan dengan pola makan serta makanan yang dikonsumsi. Sosial ekonomi juga berpengaruh pada akses informasi budaya luar dan rangsangan psikis pada siswi. Tingkat pendidikan orangtua siswi juga dapat menentukan pengetahuan,sikap,dan keterampilan dalam menyajikan makanan keluarga dan selanjutnya berpengaruh terhadap status gizi keluarga terutama anak usia sekolah. Perilaku konsumsi makanan dirumah tangga dipengaruhi oleh tingkat pengetahuan tentang gizi. Kurangnya pengetahuan tentang gizi dan menu makanan dapat menyebabkan kesalahan dalam pemilihan bahan makanan dan cara pemberian makanan pada anak walaupun makanan tersedia. Kemampuan mencukupi kebutuhan gizi anak akan mempengaruhi menarche dini ${ }^{15}$.

Berdasarkan tabel 2. menunjukkan bahwa dari 38 siswi dengan aktivitas fisik kurang aktif mengalami usia menarche normal sebesar $65,8 \%$ Hasil uji statistik variabel aktivitas fisik dengan usia menarche diperoleh tidak ada hubungan yang bermakna antara aktivitas fisik dengan usia menarche dengan nilai $\mathrm{p}=$ $0,080$ ( $p>0,05)$.

Penelitian ini sejalan dengan penelitian Aryati (2007) pada siswi SD dan SLTP di
Bandung menyatakan tidak ada perbedaan usia menarche antara responden dengan kegiatan fisik tidak aktif dengan kegiatan fisik aktif. Menurut Aryati (2007) adanya hubungan tidak bermakna diduga salah satu penyebabnya adalah karena aktivitas yang dilakukan responden adalah aktivitas yang bukan kegiatan fisik seperti olahraga namun lebih kepada kegiatan ekstrakulikuler. Data responden menunjukkan sebesar $49,0 \%$ tidak melakukan olahraga rutin sementara pola makan remaja cenderung mengonsumsi makanan yang berlemak sehingga tingkat persentase lemaknya meningkat. Persentase lemak yang tinggi dapat memicu terjadinya menarche ${ }^{15}$.

Olahraga atletik untuk remaja putri sangat baik untuk meningkatkan kesehatan, walapun memiliki efek positif dan efek negatif pada beberapa proses fisiologi seperti pertumbuhan, reproduksi, dan pertumbuhan tulang. Aktivitas fisik yang adekuat (olahraga ringan atau normal) yang dilakukan secara rutin dapat memberikan keuntungan yaitu meningkatkan kekuatan dan berhubungan erat dengan kematangan seksualitas. Aktivitas fisik berlebihan dan asupan makanan (intake) tidak adekuat dapat menunda usia menarche ${ }^{16}$.

Penelitian tersebut bertentangan dengan penelitian Veronika (2012) yang menyatakan bahwa ada hubungan antara aktivitas fisik dengan usia menarche, yaitu responden yang tidak melakukan olahraga lebih lambat menarche, dibandingkan dengan yang melakukan olahraga ( $\mathrm{p}=$ 0,038) ${ }^{17}$. Penelitian Bagga (2000) juga mengungkapkan bahwa penurunan usia menarche pada remaja putri (9-11) tahun terjadi pada remaja yang aktif melakukan olahraga $^{18}$. Menurut Karapanou (2010) hal 
ini disebabkan oleh aktivitas fisik yang berat akan menunda menarche melalui mekanisme hormonal dengan menurunkan produksi progesterone yang menyebabkan adanya penundaan kematangan endometrium ${ }^{3}$.

Menurut teori dan bukti-bukti telah menunjukkan adanya hubungan sebab akibat bertambahnya aktivitas olahraga yang berat dengan meningkatnya kejadian menarche yang terlambat (Amenorrhea primer), dengan fakta bahwa semakin tinggi keahlian seorang atlit wanita, semakin menyebabkan keterlambatan menarche ${ }^{19}$.

Sehubungan dengan ini diketahui bahwa latihan dapat meningkatkan hormon prolaktin yang dihasilkan oleh hipofisis anterior dan bertanggungjawab akan produksi ASI. Pada atlit remaja putri prolaktin mempengaruhi kematangan ovarium, yang berefek menekan dan menghambat kematangan ovarium yang dilakukan hormon FSH, hal ini mengakibatkan keterlambatan menarche atau transient amenorrhic (absence of the menses) kondisi ini sama seperti keadaan ibu yang sedang menyusui ${ }^{19}$.

Menurut peneliti, hasil penelitian yang berbeda dengan teori yang dikemukakan, dikarenakan siswi di sekolah tersebut sebesar 59,3\% aktif melakukan aktivitas fisik dan usia menarche prekoks. Hal tersebut disebabkan siswi melakukan aktivitas fisik dengan mengikuti kegiatan ekstrakurikuler disekolah seperti kegiatan ektrakurikuler yang wajib diikuti adalah pramuka, tanpa melakukan olahraga rutin sementara pola makan remaja cenderung baik. Pada siswi SDN 47/IV Kota Jambi memiliki status gizi gemuk (overweight) sebesar $60,6 \%$ dan mengalami usia menarche prekoks, sehingga meningkatnya berat badan dan lemak dalam tubuh yang nantinya akan memicu terjadinya menarche. Persentase lemak diketahui dari berat badan yang berhubungan dengan status gizi remaja putri. Kurangnya ketersediaan energi terkait dengan tingginya tingkat pengeluaran energi atau kekurangan asupan zat gizi dapat mengakibatkan disfungsi reproduksi. Disfungsi tersebut dapat mengakibatkan terjadinya amenore. Amenore dan disfungsi menstruasi disebabkan oleh penurunan berat badan atau terjadi karena malnutrisi.

Siswi atau remaja putri yang melakukan aktivitas fisik berat atau seorang atletik harus menjaga pola makan dengan baik agar tidak menimbulkan kelelehan dan kehilangan nafsu makan, sehingga tidak menurunnya berat badan dan lemak dalam tubuh yang nantinya akan memicu terjadinya keterlambatan menarche.

\section{Kesimpulan}

1. Usia rata-rata menarche siswi adalah $9,8 \pm 0,81$ tahun dengan minimal 9 tahun dan maksimal 11 tahun.

2. Responden mengalami usia menarche normal sebesar $55,4 \%$.

3. Responden dengan status gizi gemuk sebesar $50,8 \%$.

4. Aktifivitas fisik responden kurang aktif sebesar 58,5\%.

5. Terdapat hubungan yang signifikan antara status gizi dengan usia menarche $(p=0,026)$. Berdasarkan hasil penelitian di SDN 47/IV Kota Jambi Tahun 2018, semakin baik status gizi pada siswi, maka semakin cepat usia menarche, dan semakin 
rendah status gizi pada siswi maka semakin lambat usia menarche.

6. Tidak ada hubungan yang signifikan $(\mathrm{p}=0,080)$ antara aktivitas fisik dengan usia menarche. Berdasarkan hasil penelitian di SDN 47/IV Kota Jambi Tahun 2018, siswi melakukan aktivitas fisik dengan mengikuti kegiatan ektrakurikuler di sekolah, tanpa melakukan olahraga rutin,sementara status gizi cenderung baik.

\section{Saran}

1. Meningkatkan perhatian terkait masalah aktivitas fisik dan gizi yang berhubungan dengan menarche. Melalui kegiatan Unit Kesehatan Sekolah (UKS), sekolah bisa melakukan pemantauan status gizi 2 kali dalam setahun secara berkala serta melalui kegiatan ekstrakurikuler yang ada di sekolah, sekolah bisa melakukan pemantauan siswi untuk melakukan kegiatan aktivitas fisik dan dapat meningkatkan kegiatan pendidikan jasmani pada siswi secara rutin.

2. Diharapkan kepada siswi untuk melakukan aktivitas fisik secara teratur agar memiliki massa tubuh ideal sehingga tidak memperbesar resiko untuk menderita penyakit setelah mengalami menarche dini (prekoks) dan menarche lambat(tarda).

3. Meningkatkan Komunikasi, Informasi, Edukasi (KIE) di sekolah melalui program UKS (Unit Kesehatan Sekolah) seperti masalah PKPR (Program Kesehatan Peduli Remaja), diberikan penyuluhan terhadap siswi untuk menjalankan pola hidup sehat dengan gizi seimbang, serta mengajak siswi membawa bekal setiap hari ke sekolah, karena usia remaja merupakan masa kritis yang dapat menentukan status gizi di masa mendatang terutama untuk calon bayi yang dilahirkan.

4. Pemantauan status gizi (berat badan dan tinggi badan) sebaiknya dilakukan pada siswi di sekolah dasar oleh Dinas Kesehatan sehingga bisa mencegah terjadinya obesitas yang berisiko menarche dini dan bisa mencegah kekurusan yang berisiko menarche lambat. Pemantauan status gizi pada tingkat sekolah dasar sebaiknya rutin dilakukan dua kali dalam setahun. Hal ini mengingat masa puncak kecepatan pertumbuhan tinggi badan (Peak High Velocity) anak terjadi sebelum menarche sehingga dapat mengurangi kejadian stunting pada anak.

\section{Daftar Pustaka}

1. Proverawati, Atikah \& Misaroh,S. 2009. Menarche mestruasi penuh makna.Yogyakarta : Nuha Medika.

2. Manuaba, I. G. D.2009. Memahami kesehatan reproduksi wanita.Jakarta: EGC.

3. Karapanou,Olga\&Papadimitriou,Anasta sios.2010. Determinant of menarche. reproductive biology and endocrinology 2010,8 : 115. Agustus 16,2017.

http://www.rbej.com/content/pdf/14777827-8-115.pdf

4. Damayanti,Dini.2001. Faktor-faktor yang berhubungan dengan umur menarche mahasiswi baru S-1 Reguler Universitas Indonesia tahun ajaran 2000/2001.Tesis.FKM UI.Depok

5. Dieny,f.2014. Permasalahan gizi pada remaja putri. Yogyakarta: Grahamedia.

6. Rosanti,Ade, dkk.2013. Status menarche dan faktor-faktor yang 
berhubungan pada siswi sdn cijantung 03 dan smpn 103 jakarta tahun 2013. http://lib.ui.ac.id/naskahringkas/201511/S52459-Ade

7. Riskesdas.2010. Laporan riset kesehatan dasar. Badan Penelitian Dan Pengembangan Kesehatan Kementerian RI

8. Notoatmdjo.2007. Kesehatan masyarakat ilmu dan seni.Jakarta : Rineka Cipta.

9. Munda,Stevany Sarah,Freddy W Wagey,John Wantania.2012. Hubungan antara imt dengan usia menarche pada siswi sd dan smp di kota manado. Jurnal : Fakultas Kedokteran Sam Ratulangi.

10. Kusharisupeni,Hardiningsih,Aulia.201

3. Faktor-faktor yang berhubungan dengan status menarche pada siswi sekolah dasar (sd) dan sekolah menengah pertama (smp) islam assyafi'iyah bekasi tahun 2013. FKM : UI.

11. Haryani.2016. Hubungan indeks massa tubuh dengan usia menarche pada siswi sekolah dasar negeri 47/iv kota jambi tahun 2016. Skripsi : FKIK UNJA.

12. Ginarhayu.2002. Analisis faktor-faktor yang berhubungan dengan usia menarche remaja puteri (9-15tahun) pada siswi sd dan sltp di jakarta timur tahun 2002. Tesis : FKM UI.

13. Wulandari,Septiana.2013. Status gizi,aktivitas fisik,dan usia menarche remaja putri. http://jki.ui.ac.id/index.php/jki/article/vi ewFile/20/20

14. Putri, Anni Kartika.2009. Hubungan antara status gizi,status menarche ibu, media massa,aktivitas olahraga dengan status menarche siswi di smp al-azhar rawalangun jakarta timur tahun 2009. Skripsi : FKM UI.

15. Aryati,Dian.2007. Usia menarche pada siswi sd dan sltp di kota bandung. Jurnal Kesehatan Masyarakat Nasional Vol. 2, No. 6, Juni 2008.

16. Bertelloni,S,et al.2006.Effects Of Sports Training in Adolescent on Growth Puberty and Bone Health, Gynecological Endocrinology.

17. Veronika, 2010, Faktor-faktor yang berhubungan dengan keterlambatan usia menarche pada remaja putri di SLTP Kecamatan Situjuah Limo Nagari Kabupaten Lima Puluh Kota. Penelitian Fakultas Keperawatan, PDF, Dowload, http://repisitory.unand.ac.id/id/

18. Bagga, A., \& Kulkarni, S.2000. Age at menarche and secular trend in Maharashtrian (Indian) girls. Acta Biologica Szegediensis, 44 (1-4), 5357.

19. Harsuki,H.2003. Perkembangan olahraga terkini (kajian para pakar) cetakan 1. PT Rajagrafindo Persada : Jakarta. 